\title{
Risk factors and socioeconomic inequalities in undernutrition among children 0-59 months of age in India
}

\author{
Thirupathi Reddy Mokalla ${ }^{1}$, Vishnu Vardhana Rao Mendu ${ }^{2 *}$ \\ ${ }^{1}$ Division of Biostatistics, ICMR-National Institute of Nutrition, Jamai-Osmania, \\ Hyderabad, Telangana, India \\ ${ }^{2}$ Department of Health Research, ICMR-National Institute of Medical Statistics, \\ MOHFW, New Delhi, India
}

\section{ARTICLE INFO \\ Received: April 6, 2019 \\ Accepted: May 28, 2019 \\ Published: June 4, 2019 \\ *CORRESPONDING AUTHOR \\ Vishnu Vardhana Rao Mendu, Scientist $\mathrm{G}$ and Director, Department of Health Research, ICMR-National Institute of Medical Statistics, MOHFW, New Delhi - 110 029, India. \\ dr_vishnurao@yahoo.com}

\section{CITATION}

Mokalla TR, Mendu VVR. (2019). Risk factors and socioeconomic inequalities in undernutrition among children 0-59 months of age in India. International Journal of Population Studies, 5(2):14-23. doi: 10.18063/ijps.v5i2.1125

\section{Copyright: (c) 2019} Mokalla TR, Mendu VVR. This is an Open-Access article distributed under the terms of the Creative Commons Attribution-Non Commercial 4.0 International License (http://creativecommons.org/ licenses/by-nc/4.0/), permitting all noncommercial use, distribution, and reproduction in any medium, provided the original work is properly cited.

\begin{abstract}
In the majority of low- and middle-income counties, child health-care dissimilarities are further aggravated by nutritional status (i.e., stunting, underweight, and wasting). In India, child malnutrition is the most important contributor to disease burden. The present study uses data from the $4^{\text {th }}$ round of the National Family Health Survey (NFHS-4), conducted in 2015-2016. We considered anthropometric indicators of unit-level data of 2, 48, and 174 children aged 0-59 months. This study examines the socio-economic inequality in nutritional status and their determinants among under-5 year children. The factors considered in the analysis were categorized as child age in months, mother's educational status, mother's nutritional-status, type of caste, wealth index, birth order, and size of a child at birth. In this study, multivariate logistic regression and concentration index (CI) have been employed to explore the effect of various factors on the child's nutritional status. The binary logistic analysis has demonstrated a significant association between child nutritional status and mother's education, mother's nutritional status, type of caste, wealth index, birth order, and size of a child at birth. The results show that the CI for stunting, underweight, and wasting were $-0.14,-0.16$, and -0.08 . Therefore, these factors were significantly high in poorer households. Our study suggests that the nutrition-specific programs to encourage nutritional adequacy, diversity, reduces the nutritional burden, and growth of child's in India.
\end{abstract}

Keywords: India; Stunting; Wasting; Underweight; Logistic regression;

Concentration index

\section{Introduction}

Maternal and child undernutrition is highly prevalent in low- and middle-income counties (LMICs), resulting in substantial increases in morbidity, mortality, death, and overall disease burden (Black, Allen, Bhutta, et al., 2008; Hosangadi, Kaslow, Giersing, et al., 2019). It accounted for almost 97 million disability-adjusted years of life among under-five children, 98\% of which occurred in LMICs (Islam, Rahman, Rahan et al., 2019). Child undernutrition in developing countries remains a significant cause for more than one-third of all child deaths under the age of five (United Nations Children Fund [UNICEF], 2011). Child malnutrition causes 3.5 million children under the age of five to die each year in the world at the third level in this age group's disease burden (Messelu and Trueha, 2016). Lack of food affects physical and intellectual growth, harms the immune system, increases morbidity and mortality possibilities (Uthman, 2012). Nutritional status stands as a result and impact indicator when assessing development in the direction of achieving the Sustainable Development Goal. Child mortality is remarkable in one of the world's problems, especially in the first 5 years of age, which is a problem for public health in African and Asian countries (Das, 2015). 
India is the second largest populated country in the world. The country accounts for nearly a third of the global burden of stunting. Over $38 \%$, or 46.6 million, children are stunted in India. While there are 51 million wasted children in the world, India alone houses 25 million (50\%) of them. In $45 \%$ of under-five child mortalities, chronic malnutrition is the underlying factor (UNICEF, 2019). The term malnutrition comprises both undernutrition and overnutrition, and it is a significant factor causing child mortality around the world (Markos, 2014). Stunting, wasting, and underweight are three widely recognized indicators of a child's physical growth and to describe the nutritional status (Khan, Zaheer and Safdar, 2019; Akombi, Agho, Merom, et al., 2017). According to National Family Health Survey (NFHS-4), the percentage of children stunted, underweight, and wasting is $38 \%, 36 \%$, and $21 \%$, respectively, whose children aged $0-59$ months (International Institute for Population Studies [IIPS], 2017).

Literature also indicates significant variations in specific risk factors for child malnutrition through the application of statistical models and several techniques (Kumar, Kumari and Singh, 2015; Messelu and Trueha, 2016; Mishra, Pandey, Chaubey, et al., 2015; Corsi, Mejía-Guevara and Subramanian, 2015; Talukder, 2017; Boah, Azupogo, Amporfro et al., 2019; Kang and Kim, 2019; Alom, Amirul and Quddus, 2009). We have employed multiple logistic regression model(s) with binary outcomes and concentration index $(\mathrm{CI})$ functions to examine the various determinants of under-nutrition and its associated risk factors in India using NFHS-4 data.

The three leading indices are used to measure the nutritional imbalance resulting in child undernutrition. Stunting (Short height for age) - is the reason for long-term nutritional inadequacy, which brings about reduced intellectual capacity, poor school execution, and delayed mental development. The results in exposure of a child to repetitive infections or diseases pose a higher risk for sickness and death, and it influences on financial productivity. In women, stunting leads to numerous obstetric intricacies as a result of a smaller pelvis. It makes them give birth to newborn children with low birth weights, and it causes infant growth which lean toward the shorter physical frame as adults (World Health Organization [WHO], 2010). Wasting (low weight for length/height) - is a symptom of acute undernutrition, which impairs the functions of the immune system. It exposes the child to infectious disease and an increased risk of death, which is also a result of insufficient food consumption or a high frequency of irresistible illnesses, particularly diarrhea (WHO, 2010). Underweight (low weight for age) - is a composite indicator of stunting and wasting, which is considered both acute and chronic malnutrition (Mishra, Pandey, Chaubey, et al, 2015). Literature has demonstrated that the mortality risk of underweight children increased (WHO, 2010)

According to the literature, child undernutrition was strongly associated with socioeconomic status such as mother's household status, education, and nutritional status, and demographic variables such as child age, birth duration, and child size at birth (Messelu and Trueha, 2016; Corsi, Mejía-Guevara and Subramanian, 2015; Talukder, 2017; Boah, Azupogo, Amporfro, et al., 2019; Kang and Kim, 2019; Alom, Amirul and Quddus, 2009; Dessie, Fentie, Abebe, et al., 2019; Mishra, Pandey, Chaubey, et al., 2015; Kumar, Kumari and Singh., 2015).

The present study aims to investigate the socio-economic, demographic, and health determinants associated with undernutrition among the under-five age of children from NFHS-4 data in India.

Therefore, the national level recent data (NFHS-4) of India are useful in understanding its causes, and to identify the determinants of undernutrition among the under-five age of children. We hope that these findings will be helpful for policymakers, researchers, and other stakeholders to formulate appropriate strategies for removing regional imbalance in terms of undernutrition in the nation and its differential attributes among Indian states.

\section{Data and Methods}

Data are used from a $4^{\text {th }}$ round of the NFHS-4, conducted by 2015-2016 (IIPS, 2017). The survey was conducted and obtained information about population, nutrition, and health information from each of the 29 states, for each of the seven union territories, of the total 640 districts in the country in India. The NFHS-4 was conducted by interviewing randomly selected women aged 15-49 and men aged 15-54. Stratified 2-stage sampling was used as the sampling design for the NFHS-4 study. In the first stage, the primary sampling units were selected, and in the second stage, the households for the study were selected. Primary sampling units with at least 300 households were divided into segments of approximately 100-150 households. Two of the segments were selected using systematic sampling with probability proportional to size. From each selected rural and urban cluster, 22 households were selected using systematic sampling. A total of 628,900 households were selected for the sample, of which 616,346 were occupied. Of the occupied households, 601,509 were successfully interviewed, for a response rate of $9 \%$. In the interviewed households, 723,875 eligible women age 15-49 were identified for individual women's interviews. Interviews were completed with 699,686 women, for a response rate of 97\%. NFHS-4 first provided district-level estimates for several significant markers. For this study, we considered 
anthropometric indicators of unit-level data of 209,377 (after excluding missing and flagged cases) children aged $0-59$ months.

\subsection{Dependent Variable}

Three markers of height-for-age, weight-for-age, and weight-for-height z-scores provide a complete picture of children's severe undernourishment; subsequently, we utilized anthropometric information on these three-pointers to study the child undernutrition. To estimate all three markers, we embraced another reference population of the WHO 2006 (Multicenter Growth Reference Study Group, 2006). As indicated by the WHO rules, if height-for-age Z-score of a child is $<2$ standard deviations (SDs), weight-for-age Z-score of a child $<2$ SDs, and weight-for-height Z-score of a child $<2$ SDs then the child is classified as stunted, underweight, and wasted, respectively. Thus, these three nutritional indices are treated as dependent variables and dichotomized. While those that were malnourished (Z- score below $-2 \mathrm{SD}$ ) were coded as one and nourished children (Z- score above $-2 \mathrm{SD}$ ) were coded as 0 .

\subsection{Independent Variable}

Three classes of elements were evaluated as independent factors; First, socio-economic and demographic variables such as wealth index (poorest, poorer, middle, richer, and richest), and religion (Scheduled Caste, Scheduled Tribe, Other Backward Class, and Other caste) are taken into consideration. Second, child characteristics such as child age in months (0-6, 7-12, 13-24, and 25-59), birth order (1, 2, 3, 4, and above), and size at birth (average, small, and large) are taken. Third, maternal characteristics considered (Maternal age 15-49 years), maternal nutritional status (underweight: Body mass index $[\mathrm{BMI}]<18.5$, normal/healthy weight: $18.5<\mathrm{BMI}<25$, and overweight/obese BMI $>25.0$ ), and mother's education (No education, $<5$ years education, 5-7 years, 8-9 years, 10-11 years, 12 years or more) are considered. For the independent variable child age, 0-6 months were taken as the reference category for stunting and underweight (Khan, Zaheer and Safdar, 2019). For wasting, the reference category was chosen as 25-59 months since children aged 0-6, 7-12, and 13-24 months age group are the most affected by wasting and severe wasting (Akombi, Agho, Merom, et al., 2017).

\subsection{Statistical Analysis}

\subsubsection{Logistic regression}

The binary logistic regression analysis was carried out to identify the factors associated with child malnutrition. Odds ratio with $95 \%$ confidence interval was used to study the effect of independent variables (namely, child age in months, mother's educational status, mother's nutritional status, type of caste, wealth index, birth order, and size of a child at birth) on dependent variables being the three indicators of nutritional status (stunting, wasting, and underweight) (Bewick, Cheek and Ball, 2005). This analysis was performed utilizing the Statistical Package for the Social Sciences (SPSS), version 19.0 software.

\subsection{2. $C I$}

It quantifies socio-economic inequality and CI for nutritional status. It can be described utilizing the concentration curve, (Y-axis) which determines the cumulative percentage of undernourished children, whereas (X-axis) determines the total percentage of children ranked by household wealth status, and it begins with the poorest wealth quintile to the richest wealth quintile. When " $y$ " takes on higher quality for poorer people, the concentration curve lies above the equality line. If the "y" takes lower confidence, the reverse is true, the health concentration curve lies below the equality line. The CI is termed as positive when the concentration curve lies below the diagonal and negative when it lies above the diagonal. Thus, the minimum and maximum value that CI assumes is -1 and +1 (Wagstaff, Paci and van Doorslaer, 1991; Giashuddin, Rahman, Rahman, et al., 2009; Kumar, Kumari and Singh et al., 2015). We calculated the corresponding indices and their CI, by the following formula for the grouped data case.

$$
C=\left(p_{1} L_{2}-p_{2} L_{1}\right)+\left(p_{2} L_{3}-p_{3} L_{2}\right)+\ldots+\left(p_{T-1} L_{T}-p_{T} L_{T-1}\right)
$$

Where $p$ is the cumulative percent of the sample ranked by economic status, $L(\mathrm{p})$ is the corresponding concentration curve ordinate, and $\mathrm{T}$ is the number of socio-economic groups (O'Donnell, van Doorslaer, Wagstaff, et al., 2008; Zere, Tumusiime, Walker, et al., 2010). 


\section{Results}

\subsection{Descriptive Statistics}

The descriptive results are presented in Table 1 . In all the data about $(248,174)$, children in the age group of $0-59$ months were analyzed. Among them, $20 \%$ of children were stunted in the age group $0-6$ months and steadily increased to $42 \%$ in the age group of 25-59 months. This indicates that the rate of stunting is found to be higher as the age increases, similar patterns in underweight. About half of the stunted children had mothers with no education, $45 \%$ of the children had mothers with $<5$ years of education. Furthermore, a similar pattern was observed among the underweight and wasted children.

The prevalence of stunted, underweight, and wasting children is declining with the rise in mother's education. Over $50 \%$ of children in the poorest households were stunted, and it was $23 \%$ among the higher economic group. The frequency of stunted children in the scheduled caste is $44 \%$, and it is decreased to $31 \%$ in general caste or other castes. Furthermore, the same was observed in underweight and wasting. About $49 \%, 43 \%$, and $22 \%$ of the children were stunted, underweight, and wasting of forth or more birth order was decreased in the birth order one. Nearly $44 \%$ of the children belonging to the scheduled cast were stunted; the prevalence of stunted children in the other caste groups was around $31 \%$. Underweight and wasted children were more among scheduled castes, and the prevalence was quite low among the other caste groups: $47 \%, 48 \%$, and $27 \%$ of the children whose mother's nutritional status was BMI $<18.50$ were stunted, underweight, and wasted. The nutritional status of children was less common among the children's mothers' BMI $>25.0$. The prevalence of stunting, underweight, and wasting decreases as the mother's nutritional status increases. The Chi-square test performed on all selected categorical variables were found significantly related to the nutritional health status of the children

\subsection{Multiple Logistic Regression Analysis}

\subsubsection{Risk factors for stunting}

As shown in Table 2, it is noted that the odds of being stunted increased after the first 6 months of life. Children in the age group of 25-59 were 3 times more likely to be stunted when compared to the children in the age group of 0-6 months. Children in the age group of 13-24 months, 7-12 months age were 3 and 1.4 times more likely to be stunted, respectively. Children with small size (lower weight) at birth were 1.5 times more likely to be stunted than children with large size (heavier weight) at birth. Children with a higher birth order were more likely to be stunted than those having lower birth order. Children with birth order four and above had 1.3 times more chances of being a shorter height for their age.

The odds ratios reduced with the increase in mother's education. Illiterate mothers were twice as more likely to be stunted as compared to children of literate mothers whose education is of 12 years or more and similar to the mother's nutritional status. Children, whose mothers' BMI was below normal, were 1.2 times more likely to be suffering from chronic malnutrition as compared to those children whose BMI was normal. Children belonging to the poorest families are facing twice the risk of being stunted as compared to those belonging to richest families. Scheduled caste/tribes and other backward class families were more likely to have stunted children than other castes.

\subsubsection{Risk factors for underweight}

From Table 2, it was found that the factor approaching as the most reliable determinant was households' wealth index. Specifically, there exists an inverse relationship between the wealth quintile and the child's nutritional status. The household with the poorest wealth status was twice more likely to have underweight children as compared to the households which belong to the richest wealth quintile. Furthermore, it was in the mother's nutritional and educational status. Children with mother's nutrition (BMI <18.50) had 1.6 times the risk of being underweight than those whose mothers who were wellnourished and the same as the risk of having malnourished children than whose mothers had an education of 12 years or more.

The present study showed that the possibility of being underweight increased with an increase in the child's age. Among the children, age group of 25-59-months, the odds ratio for underweight was 2 times than children in the $0-6$ month's age group. Children with a smaller size at birth were 1.7 times more likely to be thinner for their age than children with a larger size at birth. Taking caste into consideration, children belonging to the scheduled caste and those belonging to other backward classes were 1.3 times more likely to be underweight. Children having birth order four and above were more prone to be underweight as compared to children having birth order 1 . 
Table 1. Sample distribution and prevalence of stunting, underweight, and wasting children between the ages of 0 and 59 month's children $(2,48$, and 174$)$ by factors at different levels, based on NFHS-4 of samples.

\begin{tabular}{|c|c|c|c|c|c|}
\hline Variables & $\mathbf{n}$ & $\%$ & Stunting & Underweight & Wasting \\
\hline Age in months & & & $(6124.75)^{*}$ & $(1490.77)^{*}$ & $(1985.74)^{*}$ \\
\hline $0-6$ & 23,768 & 9.6 & 20.3 & 26.2 & 29.4 \\
\hline $7-12$ & 23,528 & 9.5 & 25.5 & 28.9 & 25.9 \\
\hline $13-24$ & 46,488 & 18.7 & 43.7 & 34.7 & 20.9 \\
\hline $25-59$ & 139,271 & 56.1 & 42.3 & 37.4 & 18.1 \\
\hline Missing & 15,119 & 6.1 & & & \\
\hline Size at birth & & & $(833.19)^{*}$ & $(1402.74)^{*}$ & $(279.33)^{*}$ \\
\hline Large & 42,073 & 17.0 & 35 & 31.2 & 19.6 \\
\hline Average size & 169,966 & 68.5 & 38.1 & 34 & 20.2 \\
\hline Small size & 29,960 & 12.1 & 46 & 44.7 & 24.5 \\
\hline Missing & 6175 & 2.5 & & & \\
\hline Birth order & & & $(2542.13)^{*}$ & $(1686.56)^{*}$ & $(47.90)^{*}$ \\
\hline 1 & 92,026 & 37.1 & 34 & 31 & 20 \\
\hline 2 & 76,094 & 30.7 & 37.2 & 33.8 & 20.2 \\
\hline 3 & 39,766 & 16.0 & 42.2 & 38 & 21.3 \\
\hline 4 and above & 40,288 & 16.2 & 48.7 & 42.6 & 21.5 \\
\hline Mother's nutritional status & & & $(3161.16)^{*}$ & $(7274.44)^{*}$ & $(2411.05)^{*}$ \\
\hline BMI $<18.45$ & 58,165 & 23.4 & 46.6 & 48.2 & 26.9 \\
\hline BMI $18.5<$ BMI $<25.0$ & 151,571 & 61.1 & 38.7 & 33.1 & 19.9 \\
\hline $\mathrm{BMI}>25.0$ & 34,451 & 13.9 & 27.3 & 20.4 & 13.1 \\
\hline Missing & 3987 & 1.6 & & & \\
\hline Wealth index & & & $(9006.39)^{*}$ & $(9445.96)^{*}$ & $(1123.86)^{*}$ \\
\hline Poorest & 65,229 & 26.3 & 51 & 48.2 & 24.9 \\
\hline Poorer & 58,870 & 23.7 & 43.1 & 38.2 & 21 \\
\hline Middle & 49,648 & 20.0 & 36.1 & 31.2 & 19.2 \\
\hline Richer & 41,207 & 16.6 & 29.4 & 26.1 & 18.2 \\
\hline Richest & 33,220 & 13.4 & 22.6 & 19.8 & 16.8 \\
\hline Mothers education & & & $(8419.24)^{*}$ & $(7836.10)^{*}$ & $(560.43)^{*}$ \\
\hline No education & 77,603 & 31.3 & 49.7 & 45.6 & 23.2 \\
\hline$<5$ years education & 15,841 & 6.4 & 45 & 39.7 & 20.9 \\
\hline 5-7 years education & 40,097 & 16.2 & 40.5 & 36.6 & 21 \\
\hline $8-9$ years education & 44,222 & 17.8 & 35.3 & 31.3 & 19.6 \\
\hline $10-11$ years education & 27,223 & 11.0 & 30 & 27.1 & 19 \\
\hline 12 years or more & 43,188 & 17.4 & 24.1 & 21.2 & 17.6 \\
\hline Caste/tribe & & & $(1538.89)^{*}$ & $(1624.13)^{*}$ & $(240.69)^{*}$ \\
\hline $\mathrm{SC}$ & 46,845 & 18.9 & 43.6 & 39.9 & 21.9 \\
\hline ST & 49,544 & 20.0 & 39.9 & 35.1 & 21.8 \\
\hline $\mathrm{OBC}$ & 97,529 & 39.3 & 39.7 & 36.6 & 21 \\
\hline Other caste & 43,191 & 17.4 & 30.8 & 27.1 & 18 \\
\hline Missing & 11,065 & 4.5 & & & \\
\hline
\end{tabular}

Figures in parenthesis are the Chi-square statistics; $\chi^{2}$ test applied for each factor. Level of significance: ${ }^{*} p<0.01$. 
Table 2. Effects of explanatory variables on child nutritional status ( $95 \%$ CI; binary logistic regression models, estimators for the selected attributes) among children (209,377) aged 0-59 months NFHS-4.

\begin{tabular}{|c|c|c|c|c|c|c|}
\hline \multirow[t]{2}{*}{ Variables } & \multicolumn{2}{|c|}{ Stunting } & \multicolumn{2}{|c|}{ Underweight } & \multicolumn{2}{|c|}{ Wasting } \\
\hline & OR & 95\% C.I. & OR & 95\%C.I. & OR & 95\% C.I \\
\hline \multicolumn{7}{|l|}{ Age in months } \\
\hline $0-6$ & 1.00 & & 1.00 & & 1.89 & $1.83-1.96$ \\
\hline $7-12$ & 1.35 & $1.28-1.41$ & 1.11 & $1.06-1.16$ & 1.55 & $1.50-1.60$ \\
\hline $13-24$ & 3.17 & $3.05-3.30$ & 1.48 & $1.42-1.54$ & 1.17 & $1.13-1.20$ \\
\hline $25-59$ & 2.94 & $2.84-3.05$ & 1.70 & $1.65-1.76$ & 1.00 & \\
\hline \multicolumn{7}{|l|}{ Size at birth } \\
\hline Large & 1.00 & & 1.00 & & 1.00 & \\
\hline Average Size & 1.09 & $1.07-1.24$ & 1.09 & $1.06-1.12$ & 1.02 & $0.99-1.05$ \\
\hline Small size & 1.47 & $1.42-1.52$ & 1.65 & $1.59-1.71$ & 1.26 & $1.21-1.31$ \\
\hline \multicolumn{7}{|l|}{ Birth order } \\
\hline 1 & 1.00 & & 1.00 & & 1.00 & \\
\hline 2 & 1.08 & $1.06-1.11$ & 1.08 & $1.06-1.10$ & 1.03 & $1.00-1.05$ \\
\hline 3 & 1.15 & $1.11-1.18$ & 1.12 & $1.09-1.15$ & 1.02 & $0.98-1.05$ \\
\hline 4 and above & 1.27 & $1.23-1.30$ & 1.15 & $1.12-1.18$ & 0.97 & 0.94-1.01 \\
\hline \multicolumn{7}{|l|}{ Mother's nutritional status } \\
\hline BMI $<18.5$ & 1.24 & $1.21-1.26$ & 1.67 & $1.63-1.70$ & 1.43 & $1.39-1.46$ \\
\hline BMI $18.5<$ BMI $<25.0$ & 1.00 & & 1.00 & & 1.00 & \\
\hline $\mathrm{BMI}>25.0$ & 0.77 & $0.75-0.80$ & 0.66 & $0.641-0.68$ & 0.68 & $0.66-0.71$ \\
\hline \multicolumn{7}{|l|}{ Mothers education } \\
\hline No education & 1.71 & $1.65-1.78$ & 1.67 & $1.61-1.72$ & 1.15 & $1.10-1.19$ \\
\hline$<5$ years education & 1.54 & $1.47-1.61$ & 1.47 & $1.40-1.54$ & 1.04 & $0.99-1.10$ \\
\hline 5-7 years education & 1.44 & $1.39-1.49$ & 1.41 & $1.37-1.47$ & 1.08 & $1.04-1.13$ \\
\hline 8-9 education & 1.28 & $1.24-1.32$ & 1.25 & $1.20-1.29$ & 1.02 & 0.98-1.07 \\
\hline 10-11 education & 1.15 & $1.10-1.19$ & 1.16 & $1.11-1.20$ & 1.05 & $1.00-1.09$ \\
\hline 12 years or more & 1.00 & & 1.00 & & 1.00 & \\
\hline \multicolumn{7}{|l|}{ Wealth index } \\
\hline Poorest & 2.14 & $2.05-2.22$ & 2.11 & $2.02-2.19$ & 1.25 & $1.19-1.30$ \\
\hline Poorer & 1.77 & $1.70-1.84$ & 1.62 & $1.56-1.68$ & 1.06 & $1.01-1.10$ \\
\hline Middle & 1.48 & $1.43-1.54$ & 1.35 & $1.30-1.40$ & 1.01 & $0.97-1.05$ \\
\hline Richer & 1.22 & $1.17-1.26$ & 1.19 & $1.14-1.23$ & 1.01 & $0.97-1.05$ \\
\hline Richest & 1.00 & & 1.00 & & 1.00 & \\
\hline \multicolumn{7}{|l|}{ Caste/tribe } \\
\hline $\mathrm{SC}$ & 1.29 & $1.25-1.33$ & 1.29 & $1.25-1.33$ & 1.11 & $1.07-1.15$ \\
\hline ST & 1.04 & $1.01-1.07$ & 0.99 & $0.96-1.03$ & 1.10 & $1.05-1.14$ \\
\hline OBC & 1.21 & $1.18-1.24$ & 1.25 & $1.21-1.28$ & 1.10 & $1.06-1.13$ \\
\hline Other caste & 1.00 & & 1.00 & & 1.00 & \\
\hline Constant & 0.08 & & 0.18 & & 0.16 & \\
\hline
\end{tabular}

For the factor child's age in months, for stunting and underweight, reference was taken as 0-6 months and for wasting, reference was taken as $25-59$ months. CI: Confidence interval and OR: Odds ratio.

\subsubsection{Risk factors for wasting}

As shown in Table 2, the strongest determinant of acute malnutrition is identified as the mother's nutritional status. The children whose mother's BMI is below normal (BMI <18.5) were at higher risk of being wasted than those of children 
whose mother's BMI is normal. Later it was observed that there was an inverse relationship between children's age and wasting, thus the odds ratio for wasting decreased with an increase in the child age. Among the children in the age group of 25-59 months were twice likely to be wasted than those of the age group between 0 and 6 months. Wasting has an inverse relationship with the mother's educational status and household wealth index. Children of mothers whose educational level is $<5$ years were 1.2 times more likely to have wasted than children of mothers whose level of education is 12 years or more. The odds of having acute malnutrition were 1.3 times more among the children belonging to the poorest family as compared to their reference. In comparison to the child belonging to other castes, SC, ST, and OBC were prone to be wasted. Babies born with smaller size were 1.3 times more possible to be wasted than that of babies born with the larger size

\subsection{CI}

The $\mathrm{CI}$ for stunting was -0.14 (standard error $\mathrm{SE}=0.04$ ), and a negative value indicates that the higher probability of being stunted is seen in poor children than their better-off peers. Similarly, the CI for underweight and wasting was observed as $-0.16(\mathrm{SE}=0.04)$ and $-0.08(\mathrm{SE}=0.02)$. These negative values imply that poor children had a higher probability than their better-off peers in underweight and wasting.

Similarly, the concentration curve for stunting, underweight, and wasting in India for the year of 2015-2016, respectively is, represented in Figure 1. The plot shows that the concentration curve for all three nutritional indices lie above the line of equality, which suggests that the burden of malnutrition was higher among the under-five aged children who have poorer wealth index. The negative sign of the CI (Table 3 ) also confirms this graphical exploration of inequality in child undernutrition.

\section{Discussion}

This study identified that the risk factors associated with child malnutrition are in terms of stunting, underweight, and wasting among 0-59 month's age children in India using the NFHS-4 data. Our study revealed that the factors (Child's age
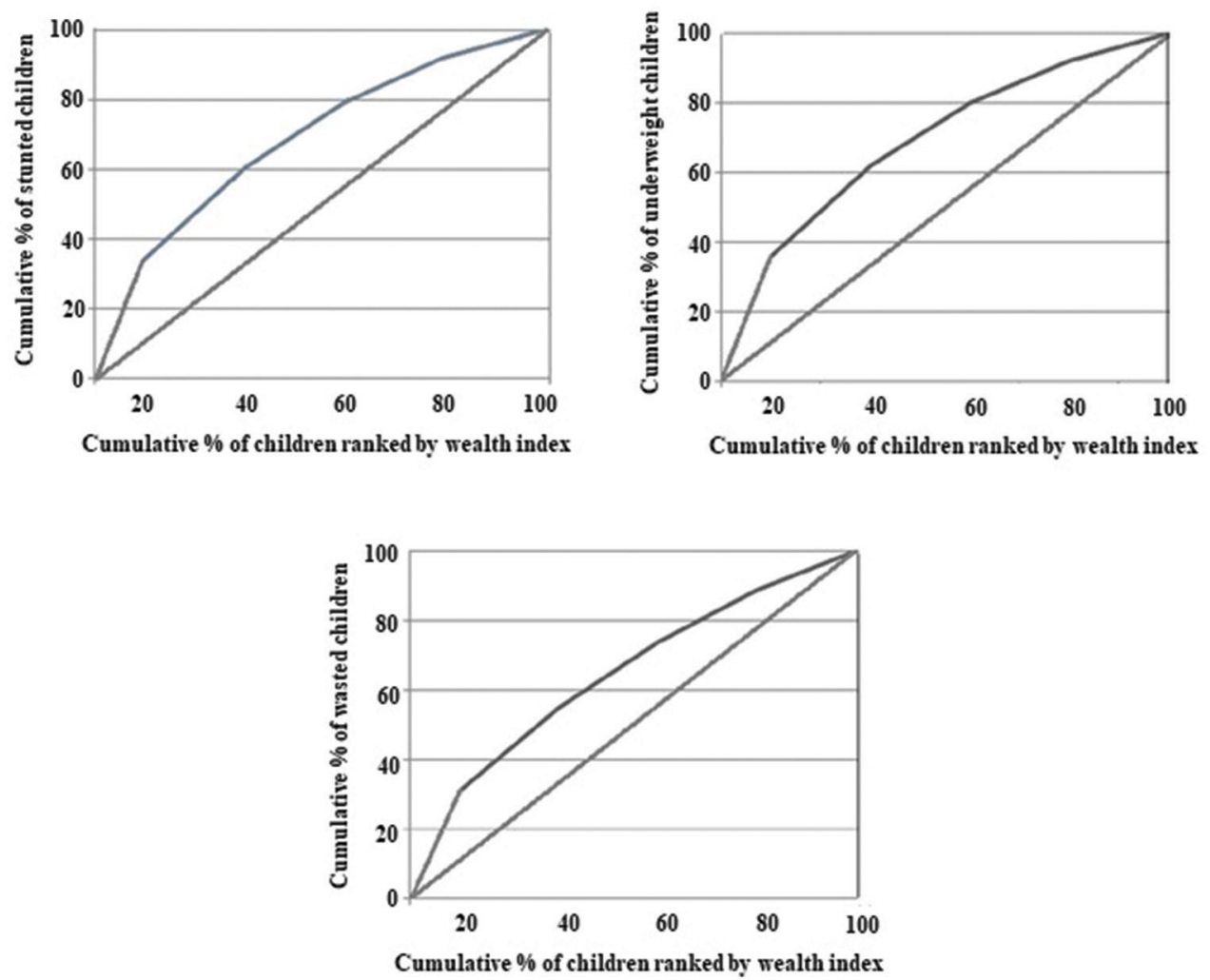

Figure 1. Concentration curves for the child malnutrition (Stunting, underweight, and wasting), India 2015-2016. 
Table 3. Child stunting, underweight and wasting prevalence and socio-economic quintile stunting, underweight, and wasting prevalence, $\%$, per quintile) among children $(248,174)$ aged $0-59$ months.

\begin{tabular}{lccccccc}
\hline & Poorest & Poorer & Middle & Richer & Richest & Concentration index & SE(CI) \\
\hline Stunting & 51.0 & 43.0 & 36.0 & 29.0 & 23.0 & -0.14 & 0.038 \\
Underweight & 48.0 & 38.0 & 31.0 & 26.0 & 20.0 & -0.16 & 0.038 \\
Wasting & 25.0 & 21.0 & 19.0 & 18.0 & 17.0 & -0.08 & 0.016 \\
\hline SE: Stand
\end{tabular}

SE: Standard error.

in months, mother's education, size of a child at birth, wealth index, type of caste, and mother's nutritional status) have a significant association with child nutritional status. Child's age in months emerged as one of the strongest determinants of the nutritional status of children. In the first 6 months of life, stunting and underweight children were least and, it increased with the increase in age. Similar findings, along with other child health-related indicators, were reported from India (Singh, Srivastava and Upadhyay, 2019; Mishra, Pandey, Chaubey, et al. 2015; Vir, 2013). In malnourishment, the size of a newborn baby at birth plays a significant role. This study reveals that children have the least risk of being malnourished if they were born healthy and large size at birth when compared to children who were born weak (Rahman and Sultana, 2019; Prado and Dewey, 2014). A child with higher birth orders is at a greater risk of being severely undernourished. It may occur due to lack of food supplementation to the children (Rahman, 2016).

Household's economic status also affects child malnutrition. In this study, we observed that odds of being stunted, underweight, and wasted were significantly higher among children with the lowest socio-economic background. Since these lower-income families are having limited access to food, health services and unable to fulfill the basic needs of children, which effects in growth and development of children (Agrawal, Farrell, Wethington, et al., 2019; Singh, Srivastava and Upadhyay, 2019). A child's nutritional status is likely to be affected by a mother's educational and nutritional status. This study shows that children of mothers with no education were more likely to be severely malnourished (stunted, underweight, and wasted) as compared to children whose mothers are educated. Hence, an association was found between maternal education and child nutritional status, which is consistent with several previous studies (Mishra, Pandey, Chaubey, et al., 2015; Khan, Zaheer and Safdar, 2019). Educated mothers are well aware of the nutritional requirements of infants, also make comparative choices of existing health services over traditional practices for improved health care of their children. Hence, they are capable of taking proper care as compared to illiterate mothers, who may contribute to the increase in malnourished children (Banerjee, Alok, Lakhtakia, et al., 2019; Hetherington and McNally, 2020). Hence, these maternal characteristics should be carefully examined for executing proper interventions to reduce the burden of child malnutrition status in India.

The present study also established a strong association between the child's and the mother's nutritional status. Healthy mothers (children whose mothers BMI is not below normal) were more likely to produce healthy and well-nourished children as compared to the unhealthy and weak undernourished mothers. Therefore, the risk of stunting, underweight, and wasting was higher in those children whose mothers' BMI was below normal. Social characteristics were also one of the significant determinants of child malnutrition other than demographic characteristics. Hence, mothers belonging to the scheduled castes or tribes were more likely to have malnourished children than those who are not from any of the sub-classes mentioned.

\section{Conclusions}

According to the findings, the poorest family children were associated with an increased risk of undernutrition when compared to the wealthiest of children. Child undernutrition causes the poorer family to bear an extra burden, resulting in more illnesses in additions to infectious and non-communicable diseases. There is an immediate need to establish services to low-income families to avoid child malnutrition. In the health sector, priority should be given to current programs for children suffering undernutrition, as well as for the most deprived group of families. The findings of this study illustrate the need to increase the level of education of parents, to improve the nutritional status of the mother and therefore achieve better nutritional status among under-five children in India.

\section{Acknowledgments}

The authors gratefully acknowledge the financial support and fellowship granted by the National Institute of Nutrition (NIN), Indian Council of Medical Research, Hyderabad, India, for carrying out the study. The authors wish to thank 
Dr. R Hemalatha (Director, NIN) for her encouragement, Dr. Subbarao M Gavaravarapu, Mr. K. Venkaiah and Dr. N. Bala Krishna for their insightful inputs. The authors would also like to thank Dr. Ramesh Athe (Assistant Professor, IIT Dharwad), Prof V. V. Haragopal (retd), Mounika Kandukuri (DST-INSPIRE Fellow) from Department of Statistics, Osmania University and Ungarala Venkat Ramakrishna (Research Scholar) from NIN.

\section{Authors' Contributions}

Thirupathi Reddy M contributed in the data collection, analysis, and manuscript preparation. Vishnu Vardhana Rao M developed the study protocol, secured funds, supervised the study, and guided in manuscript preparation.

\section{Conflicts of Interest}

There are no conflicts of interest associated with this work.

\section{References}

Agrawal T, Farrell TJ, Wethington E and Devine CM. (2019). Change and Continuity in Low-Income Working Mothers' Food Practices for Young Children in Response to Life Events. Maternal and Child Health Journal, 23(9):1206-1212.

Akombi BJ, Agho KE, Merom D, Hall JJ and Renzaho AM. (2017). Multilevel Analysis of Factors Associated with Wasting and Underweight among Children under-five Years in Nigeria. Nutrients, 9(1):E44.

Alom J, Amirul M and Quddus IM. (2009). Socioeconomic Factors Influencing Nutritional Status of Under-Five Children of Agrarian Families in Bangladesh: A Multilevel Analysis. Bangladesh Journal of Agricultural Economics, 1(2):63-74. Available from: https://wwwageconsearch.umn.edu/bitstream/200132/2/Article_05 Vol-XXXII.pdf. [Last accessed on 2018 Mar 14].

Banerjee S, Alok S, Lakhtakia S and Mahapatra MS. (2019). Determinants of Women Empowerment and Effect on Children's Overall Health Development. IASSI Quarterly, 38(2):276-291.

Bewick V, Cheek L and Ball J. (2005). Statistics Review 14: Logistic Regression. Critical care (London, England), 9(1):112-118.

Black RE, Allen LH, Bhutta ZA, Caulfield LE, de Onis M, Ezzati M and Rivera J. (2008). Maternal and Child Undernutrition: Global and Regional Exposures and Health Consequences. The Lancet, 371(9608):243-260.

Boah M, Azupogo F, Amporfro DA and Abada LA. (2019). The Epidemiology of Undernutrition and its Determinants in Children under Five Years in Ghana. PLoS One, 14(7):e0219665.

Corsi DJ, Mejía-Guevara I and Subramanian SV. (2015). Risk Factors for Child Chronic Undernutrition in India: Estimating Relative Importance, Population Attributable Risk and Fractions. Social Science and Medicine, 157:165-185.

Das AC. (2015). Childhood Mortality and Child Nutritional Status of Bangladesh: A Review on Demographic and Health Survey. Journal of Current and Advance Medical Research, 2(2):42.

Dessie ZB, Fentie M, Abebe Z, Ayele TA and Muchie KF. (2019). Maternal Characteristics and Nutritional Status among 6-59 Months of Children in Ethiopia: Further Analysis of Demographic and Health Survey. BMC Pediatrics, 19(1):83.

Giashuddin SM, Rahman A, Rahman F, Mashreky SR, Chowdhury SM, Linnan M and Shafinaz S. (2009). Socio-economic Inequality in Child Injury in Bangladesh Implication for Developing Countries. International Journal for Equity in Health, 8:7.

Hetherington MM and McNally J. (2020). Reading Appetite Cues in Infancy: A Role for Nutrition Education. In: Nutrition Education: Strategies for Improving Nutrition and Healthy Eating in Individuals and Communities. Vol. 92. Berlin, Germany: Karger Publishers. p41-51.

Hosangadi D, Smith PG, Kaslow DC and Giersing BK. (2019). WHO Consultation on ETEC and Shigella burden of Disease, Geneva, 6-7 $7^{\text {th }}$ April 2017: Meeting Report. Vaccine, 37(50):7381-7390.

IIIPS. (2017). National Family Health Survey (NFHS-4) 2015-16 India. Mumbai, Maharashtra: International Institute for Population Sciences (IIPS) and ICF.

Islam MR, Rahman MS, Rahman MM, Nomura S, De Silva A, Lanerolle P and Rahman MM. (2019) Reducing Childhood Malnutrition in Bangladesh: The Importance of Addressing Socio-Economic Inequalities. Public Health Nutrition, 23(1):72-82.

Kang Y and Kim J. (2019). Risk Factors for Undernutrition among Children 0-59 Months of Age in Myanmar. Maternal and Child Nutrition, 15(4):e12821. 
Khan S, Zaheer S and Safdar NF. (2019). Determinants of Stunting, Underweight and Wasting among Children $<5$ Years of Age: Evidence from 2012-2013 Pakistan Demographic and Health Survey. BMC Public Health, 19(1):358.

Kumar A, Kumari D and Singh A. (2015). Increasing Socio-economic Inequality in Childhood Undernutrition in Urban India: Trends between 1992-93, 1998-99 and 2005-06. Health Policy and Planning, 30(8):1003-1016.

Markos Z. (2014). Predicting Under Nutrition Status of Under-Five Children Using Data Mining Techniques: The Case of 2011 Ethiopian Demographic and Health Survey. Journal of Health and Medical Informatics, 5(2):2-11.

Messelu Y and Trueha K. (2016). Determining Risk Factors of Malnutrition among under Five Children in Sheka Zone, South West Ethiopia Using Ordinal Logistic Regression Analysis. Public Health Research, 6(6):161-167.

Mishra S, Pandey CM, Chaubey YP and Singh U. (2015). Determinants of Child Malnutrition in Empowered Action Group (EAG) States of India. Statistics and Applications, 13(13):2454-7395.

Multicentre WHO, Reference G and Group S. (2006) WHO Child Growth Standards Based on Length/height, Weight and Age. Acta Paediatrica, 450:76-85.

O'Donnell O, van Doorslaer E, Wagstaff A and Lindelow M. (2008). Analyzing Health Equity Using Household Survey Data. Washington, DC: Health Equity Using.

Prado EL and Dewey KG. (2014). Nutrition and Brain Development in Early Life. Nutrition Reviews, 72(4):267-284. Available from: https://www.academic.oup.com/nutritionreviews/article-abstract/72/4/267/1859597. [Last accesses on 2020 Apr 29].

Rahman M and Sultana P. (2019). Distribution and Risk Factors of Child Malnutrition in Bangladesh, based on Bangladesh Demographic and Health Survey-2014 Data. Journal of Biometrics and Biostatistics, 10(1):425.

Rahman M. (2016). Association between 004Frder of Birth and Chronic Malnutrition of Children: A Study of Nationally Representative Bangladeshi Sample. Cadernos de Saúde Pública, 32(2):e00011215.

Singh S, Srivastava S, and Upadhyay AK. (2019). Socio-Economic Inequality in Malnutrition among Children in India: An Analysis of 640 Districts from National Family Health Survey (2015-16). International Journal for Equity in Health, 18(1):203.

Talukder A. (2017). Factors Associated with Malnutrition among Under-Five Children: Illustration using Bangladesh Demographic and Health Survey, 2014 Data. Children, 4(10):88.

UNICEF. (2011). The Situation of Children in India A Profile. UNICEF India. Available from: http://www.unicef.in. [Last accessed on 2018 Feb 23].

UNICEF. (2019). Reducing Stunting and Wasting in Children and Women. UNICEF India. Available from: https://www.unicef.org/ india/reports/reducing-stunting-and-wasting-children-and-women. [Last accessed on $2020 \mathrm{Apr} 28$ ].

Uthman O. (2012). A multilevel Analysis of the Effect of Household Wealth Inequality on under-five Child under-nutrition: Evidence from the 2003 Nigeria Demographic and Health Survey. The Internet Journal of Nutrition and Wellness, 6(2):1-9.

Vir, S. (2013). Community Based Maternal and Child Health Nutrition Project, Uttar Pradesh: An Innovative Strategy Focusing on "at Risk” Families. Indian Journal of Community Medicine, 38(4):234-239.

Wagstaff A, Paci P and van Doorslaer E. (1991). On the Measurement of Inequalities in Health. Social Science and Medicine, 33(5):545-557.

World Health Organization. (2010). Interpretation Guide Nutrition Landscape Information System (NLIS). Geneva: World Health Organization.

Zere E, Tumusiime P, Walker O, Kirigia J, Mwikisa C and Mbeeli T. (2010). Inequities in Utilization of Maternal Health Interventions in Namibia: Implications for Progress Towards MDG 5 Targets. International Journal for Equity in Health, 9:16. 